\title{
Relationship between Lower Limb Muscle Structure and Function in Cerebral Palsy
}

\author{
In-Hee Ko, PT, MSc'1), Jung-Hee Kim, PT, MSc ${ }^{1)}$, Byoung-Hee Lee, PT, PhD ${ }^{1 *}$ \\ 1) Graduate School of Physical Therapy, Sahmyook University: 815 Hwarang-ro, Nowon-gu, Seoul \\ 139-742, Republic of Korea
}

\begin{abstract}
Purpose] The purpose of the study was to provide information for intervention by comparing lower limb muscle thickness, gross motor function and functional level of activity daily living between cerebral palsy (CP) and mental retardation (MR). [Subjects] Sixty subjects participated: $38 \mathrm{CP}$ and 9 MR subjects and 13 normally developing infants. [Methods] Ultrasonography and a manual muscle tester were used for measuring the thickness and strength of knee extensor and ankle plantar flexor muscles. The Gross Motor Function Measure (GMFM) and Wee Functional Independence Measure (WeeFIM) were used to evaluate level of gross motor and independence level. [Results] Knee extensor thicknesses of CP and MR subjects were thinner than those of normally developing infants. Strengths of knee extensor and ankle plantar flexor showed differences being strongest in normally developing infants, followed by MR, and CP. Subjects in the examination of GMFM, there were no significant differences between CP and MR. A decline in social cognition of MR subjects was found in the examination of WeeFIM. [Conclusion] CP and MR subjects had smaller muscle thicknesses and strengths than those of normally developing infants, and lower gross motor function and functional independent level.

Key words: Cerebral palsy, Mental retardation, Muscle thickness
\end{abstract}

(This article was submitted Jun. 27, 2013, and was accepted Aug. 4, 2013)

\section{INTRODUCTION}

Cerebral palsy is an abnormality related to mobility and postural development due to lack of development progression in the brain of an unborn child in the developmental phase or a baby. It encompasses sensory, cognition, communication, behavior disorders including motor disorder and spasticity ${ }^{1}$. Motor disorders with cerebral palsy characteristics limit physical activity leading to lack of experience with motor activity which would delay concept formation about sensation and motor activity, sociality etc, therefore it imposes many limitation on social activity and participation $^{2)}$.

Cerebral palsy may involve problems in the neuromuscular system such as spasticity, contracture, muscle weakness, and loss of selective movement ${ }^{3)}$. The gastrocnemius is involved in weight bearing during gait, and plays the main role in adjusting the angle of the ankle in the stance and swing phases ${ }^{4}$. The length of the gastrocnemius and the ankle range of motion is lower in cerebral palsy subjects than in normally developing infants, and this is known to adversely affect gait ${ }^{5}$. The quadriceps femoris is essential for functional activities involving weight-support, such as

*Corresponding author. Byoung-Hee Lee (e-mail: 3679@syu. ac.kr)

(C)2014 The Society of Physical Therapy Science

This is an open-access article distributed under the terms of the Creative Commons Attribution Non-Commercial No Derivatives (by-ncnd) License $<$ http://creativecommons.org/licenses/by-nc-nd/3.0/>. moving from the sitting position to the standing posture, climbing up and down the stairs, and adjusting against gravity in the stance phase during gate ${ }^{6}$.

Children with cerebral palsy show weakened muscle due to lack of motor unit activation and thickness of $50 \%$ of small muscles, compared to children with normal development ${ }^{7)}$. cerebral palsy with capability of independent ambulation also had limitation on muscle contraction in that its greatest ability of muscle contraction only reached $52 \%$ of that of normally developed children ${ }^{8)}$, regular physical activity ameliorates, but does not prevent age-related atrophy of lower extremity muscles ${ }^{9}$. The Gross Motor Function Measure (GMFM) and computerized gait analysis are commonly used to assess patients with cerebral palsy (CP). Knee extensor strength correlated directly with the $\mathrm{GMFM}^{10)}$. Primary weakness and secondary disuse of this muscle group, coupled with abnormal movement patterns, may lead to muscle atrophy and rearrangement of the internal muscle architecture, thus adversely affecting function $^{11)}$. But, few studies of the muscle structure and body function of cerebral palsy subjects have been performed. Therefore, the purpose of this study was to provide the information necessary for intervention by comparing the muscle thicknesses, gross motor functions, activities of daily living of the main lower limb muscles and functional levels of activity of daily living between cerebral palsy and mental retardation subjects.

\section{SUBJECTS AND METHODS}

The subjects of this study were 38 cerebral palsy chil- 
dren (21 males and 17 females) who were diagnosed as having diplegic cerebral palsy (GMFCS Level I, n=10; Level II, $\mathrm{n}=6$; Level III, $\mathrm{n}=22$ ) and were receiving physical therapy at the Kyeung-ki-do G Rehabilitation Hospital, 13 normally developing infants ( 8 males and 5 females), and 9 mental retardation subjects (4 males and 5 females) with no other underlying disease, a total of 60 subjects. The specific selection criteria were as follows: no orthopedic surgery within the last 6 months, and no botulin or bacropen treatments of the lower limbs during the previous 3 months. Subjects with epilepsy were excluded from this study ${ }^{12}$. The present study was approved by Sahmyook University Institutional Review Board (SYUIRB2012-030). A subject was explained the objective of the study and its requirements, and all those who participated provided written parental consent.

Movable ultrasonic waves (Mysono U5, Medison Korea, 2009) were used to measure the muscle thicknesses of the rectus femoris and gastrocnemius. Subjects were made comfortable in the prone position with knee extension, and the distance between the superior aponeurosis and the inferior aponerosis of the gastrocnemius was measured as the thickness of the gastrocnemius ${ }^{13)}$. An intra-rater reliability of $r=0.98: 1.0$, and an inter-rater reliability of $r=0.93: 0.98$ have been reported for ultrasonic waves imaging ${ }^{14)}$.

An manual muscle tester (model 11001163, Lafayette Instruments, USA, 2003) was used to evaluate the muscle strength of the knee extensor and plantar flexor muscles. Subjects sat on a chair with the trunk fixed, and the knees flexed at 90 degrees and performed maximum isometric contraction for measurement of knee extensor strength. During this time, the degree of contraction of the quadriceps femoris was measured using the manual muscle tester. Subjects sat on the chair with the trunk fixed, and the knee and ankle joints at 90 degrees. The ankle was fixed in the central position by supporting the foot heel with a foot stand. Then, maximum isometric contraction was performed for the measurement of ankle extensor. Three measurements were made on both sides, and the average value was calculated ${ }^{15)}$. An intra-rater reliability for the manual muscle tester of $r=0.84: 0.99$, and an inter-rater reliability for the manual muscle tester of $r=0.84: 0.94$ have been reported ${ }^{16)}$.

The Gross Motor Function Measure (GMFM) was used to evaluate the gross motor function. GMFM is divided into 5 domains, which are A (lying and rolling), B (sitting), C (quadruped and kneeling), D (standing), E (walking, running, jumping), encompassing 88 items. Inter-rater reliability for GMFM of $r=0.77$, a test-retest reliability for GMFM of $r=0.88$, and intra-rater reliability for GMFM of $r=0.68$ have been reported ${ }^{17,18)}$.

The Wee Functional independence measure (WeeFIM) was used to evaluate the health of the subjects, their developmental condition, educational level conditions and degree of local sociality. Items of the WeeFIM are scored from 1 to score 7 which is a condition of complete independent. The lowest possible score is 18 and the highest possible score is $126^{19)}$. An inter-rater reliability of 0.92 , a test-retest reliability of 0.99 , and an intra-rater reliability of 0.81 have been reported for the WeeFLM ${ }^{20)}$.
The SPSS 18.0 program was used for statistical analyses. The Shapiro-Wilk test was used for determination of the general properties and variables of the subjects. The independent $t$ test was used for the comparison of GMFM and WeeFIM between cerebral palsy and mental retardation subjects, and one-way ANOVA was performed for comparison of the means of muscle thickness and strength among the subjects groups. A post-hoc test using the Scheffe method was employed for comparison of each group. A p value under 0.05 was considered significant.

\section{RESULTS}

General characteristics of subjects for study are as follows (Table 1).

Differences in muscle thicknesses of the rectus femoris and gastrocnemius according to the posture are presented in Table 2. The average thickness of the rectus femoris in the standing position was $12.69 \mathrm{~mm}$ for normally developing infants, $11.89 \mathrm{~mm}$ for cerebral palsy subjects and $10.14 \mathrm{~mm}$ for mental retardation subjects, with significant differences among the groups $(p<0.05)$. The average thickness of the rectus femoris in the supine position was $16.13 \mathrm{~mm}$ for normally developing infants, $14.55 \mathrm{~mm}$ for cerebral palsy subjects, and $12.63 \mathrm{~mm}$ for mental retardation subjects, with significant differences among the groups $(p<0.05)$. The average strength of the knee extensor was $17.77 \mathrm{~kg}$ for normally developing infants, $7.92 \mathrm{~kg}$ for cerebral palsy subjects and $11.19 \mathrm{~kg}$ for mental retardation subjects, with significant differences $(\mathrm{p}<0.01)$. The average strength of the ankle plantar flexor was $15.54 \mathrm{~kg}$ for normally developing infants, $6.01 \mathrm{~kg}$ for cerebral palsy subjects, and $7.82 \mathrm{~kg}$ for mental retardation subjects, with significant differences among the groups $(\mathrm{p}<0.01)$. Normally developing infants' rectus femoris was thicker than that of cerebral palsy, and mental retardation subjects, according to the post hoc test. Knee extensor and ankle plantar flexor strengths were the strongest for normally developing infants, followed by mental retardation and cerebral palsy subjects, according to the post hoc test.

The results of comparison of the GMFM, and WeeFIM between cerebral palsy and mental retardation are presented in Table 3. There was a significant difference in the average scores of social cognition in the WeeFIM: 16.68 for cerebral palsy subjects, and 11.56 for mental retardation subjects $(\mathrm{p}<0.05)$.

\section{DISCUSSION}

Cerebral palsy's problems due to motor disorder may lead to limitation of body activity and lack of exercise (motor) experience that may delay development of sensation, conceptual formation about motor control and sociality, etc ${ }^{2)}$. Cerebral palsy typically involves a variety of neuromuscular and musculoskeletal problems. These problems include spasticity, dystonia, contractures, abnormal bone growth, poor balance, and loss of selective motor control $^{3)}$. A previous study of the muscle structure of cerebral palsy subjects investigated the formation of the gastrocnemius and hamstrings using ultrasound and reported the pennation angle 
Table 1. General characteristics of the participants

\begin{tabular}{lccc}
\hline & $\begin{array}{c}\text { Normal development } \\
\text { infant }(\mathrm{n}=13)\end{array}$ & $\begin{array}{c}\text { Cerebral palsy } \\
(\mathrm{n}=38)\end{array}$ & $\begin{array}{c}\text { Mental retardation } \\
(\mathrm{n}=9)\end{array}$ \\
\hline Sex (male/female) & $8 / 5$ & $21 / 17$ & $4 / 5$ \\
Age (month) & $79.6(24.0)^{\text {a }}$ & $66.6(15.7)$ & $53.8(17.9)$ \\
Height $(\mathrm{cm})$ & $120.3(16.7)$ & $107.6(6.6)$ & $102.4(9.2)$ \\
Weight $(\mathrm{kg})$ & $21.3(5.6)$ & $18.3(3.2)$ & $16.6(3.0)$ \\
\hline
\end{tabular}

Values are a mean (SD).

Table 2. Comparison of muscle thickness and strengths among the groups

\begin{tabular}{lllcc}
\hline & & NDI $(\mathrm{n}=13)$ & $\mathrm{CP}(\mathrm{n}=38)$ & $\mathrm{MR}(\mathrm{n}=9)$ \\
\hline & RF in standing & $12.69(1.97)^{*}, \mathrm{a}$ & $11.89(2.05)^{\mathrm{b}}$ & $10.14(2.51)$ \\
Muscle thickness & RF lying & $16.13(3.07)^{*}, \mathrm{a}$ & $14.55(2.33)^{\mathrm{b}}$ & $12.63(1.85)$ \\
& Gastrocnemius standing & $11.46(1.55)$ & $11.90(2.57)$ & $12.55(3.06)$ \\
& Gastrocnemius lying & $15.41(2.42)$ & $14.72(3.68)$ & $14.34(3.78)$ \\
Muscle strength & Knee extensor & $17.77(5.45)^{*}, \mathrm{c}$ & $7.92(4.82)$ & $11.19(5.85)^{\mathrm{d}}$ \\
& Plantar flexor & $15.54(7.51)^{*, \mathrm{c}}$ & $6.01(4.11)$ & $7.82(3.04)^{\mathrm{d}}$ \\
\hline
\end{tabular}

Values are mean (SD). NDI: normally developing infants; CP: cerebral palsy; MR: mental retardation; RF: rectus femoris; * $<0.05$ from mean among the three groups; a, NDI is significantly greater than CP and MR; $\mathrm{b}, \mathrm{CP}$ is significantly greater than MR; c, NDI is significantly stronger than CP and MR; d, MR is significantly stronger than $\mathrm{CP}$ according to the post hoc test.

Table 3. Comparison of GMFM and WeeFIM between CP and MR

\begin{tabular}{llcc}
\hline & & $\mathrm{CP}(\mathrm{n}=38)$ & $\mathrm{MR}(\mathrm{n}=9)$ \\
\hline & Lying \& Rolling & $97.76(8.42)$ & $100.00(0.00)$ \\
& Sitting & $95.00(10.00)$ & $97.78(3.93)$ \\
(score) & Crawling \& Kneeling & $80.42(18.49)$ & $84.11(24.01)$ \\
& Standing & $53.95(30.76)$ & $68.89(34.03)$ \\
& Walking, Running \& Jumping & $39.47(33.32)$ & $60.56(39.22)$ \\
& total & $73.34(17.71)$ & $82.33(19.95)$ \\
\hline \multirow{4}{*}{ WeeFIM } & Self-care & $27.21(11.89)$ & $28.00(11.63)$ \\
& Bladder \& Bowel control & $12.05(3.67)$ & $12.33(3.04)$ \\
& Ambulation & $12.95(6.81)$ & $15.33(6.44)$ \\
& Place transfer & $8.18(4.69)$ & $9.11(5.48)$ \\
& Conversation & $11.16(3.82)$ & $8.89(3.51)$ \\
& Social cognition & $16.68(6.01) *$ & $11.56(5.10)$ \\
& total & $88.24(31.39)$ & $85.22(21.73)$ \\
\hline
\end{tabular}

Values are mean (SD). ${ }^{*} \mathrm{p}<0.05$ from mean between the two groups

of the gastrocnemius was 10 degrees, the pennation angle of the plantar flexor was 10 degrees, and the pennation angle of the dorsi flexor was 10 degrees $^{5}$. Compared to normally developing infants, in cerebral palsy subjects, the pennation angle of the calf muscle and the range of motion of the ankle were smaller, and this may be a cause of decrease in physical activity. Therefore, structural problems of the muscle are the main factor affecting muscular function and decrease in activity ${ }^{21)}$. The gastrocnemius, one of the lower extremity muscles, plays an important role in supporting weight in gait, and in adjusting the angle of the ankle in the stance and swing phases.

When compared with normally developing infants, and there were significant differences in cerebral palsy subjects' gastrocnemius and rectus femoris thicknesses ${ }^{5,11)}$. Significant differences between the thickness of the postural rectus femoris of children with cerebral palsy and mental retardation were shown in this study $(\mathrm{p}<0.05)$, as well as significant differences in knee extensor and plantar flexor strengths $(p<0.01)$. These results agree the results of earlier studies ${ }^{22)}$. The rectus femoris and gastrocnemius of childen with cerebral palsy were thicker than those of childen with mental retardation; however, knee extensor and plantar flexor strengths of childen with mental retardation were stronger. Generally, strength is proportional to the diameter of the muscle. Compared to children with mental re- 
tardation, the rectus femoris and gastrocnemius of children with cerebral palsy were thicker, yet their strengths were less strong. This is because of spasticity in the muscle in cerebral palsy, which results in pseudo atrophy. In the comparison of the GMFM and WeeFIM between children with cerebral palsy and mental retardation, there were no significant differences except for the item of social cognition. However, cerebral palsy children showed limitations in basic ability of movement which appeared as lower scored in the items of standing, walking, running in GMFM. Limitations of functional activity were shown by both groups of children in the WeeFIM. Children with mental disability showed a significant difference from children with cerebral palsy in the item of social cognition showing a problems with reciprocal action that is necessary for social activity.

It's difficult to assume that the sample of the study is representative of the population, because of the small sample numbers, and the disparities in size between the different groups of children. In addition, this study only compared muscle thickness, strength and function, standards of activity and participation using cross sectional design. Therefore, further correlation analysis of each of the items and further study into effective intervention methods for improvement of function are needed.

\section{REFERENCES}

1) Bax M, Goldstein $M$, Rosenbaum $P$, et al.: Proposed definition and classification of cerebral palsy. Dev Med Child Neurol, 2005, 47: 571-576. [Medline] [CrossRef]

2) Elder GC, Kirk J, Stewart G, et al.: Contributing factors to muscle weakness in children with cerebral palsy. Dev Med Child Neurol, 2003, 45: 542-550. [Medline] [CrossRef]

3) Gormley ME: Treatment of neuromuscular and musculoskeletal problems in cerebral palsy. Pediatr Rehabil, 2001, 4: 5-16. [Medline]

4) Damiano DL, Quinlivan J, Owen BF, et al.: Spasticity versus strength in cerebral palsy: relationships among involuntary resistance, voluntary torque, and motor function. Eur J Neurol, 2001, 8: 40-49. [Medline] [CrossRef]

5) Gao F, Zhao H, Gaebler-Spira D, et al.: In vivo evaluations of morphologic changes of gastrocnemius muscle fascicles and achilles tendon in children with cerebral palsy. Am J Phys Med Rehabil, 2011, 90: 364-371. [Medline] [CrossRef]

6) Mizner RL, Snyder-Mackler L: Altered loading during walking and sit-to- stand is affected by quadriceps weakness after total knee arthroplasty. J Orthop Res, 2005, 23: 1083-1090. [Medline] [CrossRef]

7) Lampe R, Grassl S, Mitternacht J, et al: MRT-measurements of muscle volumes of the lower extremities of youths with spastic hemiplegia caused by cerebral palsy. Brain Dev, 2006, 28: 500-506. [Medline] [CrossRef]

8) Wiley ME, Damiano DL: Lower-extremity strength profiles in spastic cerebral palsy. Dev Med Child Neurol, 1998, 40: 100-107. [Medline] [CrossRef]

9) Reimers CD, Harder T, Saxe H: Age-related muscle atrophy does not affect all muscles and can partly be compensated by physical activity: an ultrasound study. J Neurol Sci, 1998, 159: 60-66. [Medline] [CrossRef]

10) Goh HT, Thompson M, Huang WB, et al.: Relationships among measures of knee musculoskeletal impairments, gross motor function, and walking efficiency in children with cerebral palsy. Pediatr Phys Ther, 2006, 18: 253-261. [Medline] [CrossRef]

11) Moreau NG, Simpson KN, Teefey SA, et al.: Muscle architecture predicts maximum strength and is related to activity levels in cerebral palsy. Phys Ther, 2010, 90: 1619-1630. [Medline] [CrossRef]

12) Thorpe DL: On "Muscle architecture predicts maximum strength" Moreau NG, Simpson KN, Teefey SA, Damiano DL. Phys Ther. 2010;90:1619 1630. Phys Ther, 2011, 91: 436, author reply 437. [Medline] [CrossRef]

13) Smith TO, Davies L, Hing CB: A systematic review to determine the reliability of knee joint position sense assessment measures. Knee, 2013, 20: 162-169. [Medline] [CrossRef]

14) McNee AE, Gough M, Morrissey MC, et al.: Increases in muscle volume after plantarflexor strength training in children with spastic cerebral palsy. Dev Med Child Neurol, 2009, 51: 429-435. [Medline] [CrossRef]

15) Krebs DE, Scarborough DM, McGibbon CA: Functional vs. strength training in disabled elderly outpatients. Am J Phys Med Rehabil, 2007, 86 : 93-103. [Medline] [CrossRef]

16) Bohannon RW, Andrews AW: Interrater reliability of hand-held dynamometry. Phys Ther, 1987, 67: 931-933. [Medline]

17) Damiano DL, Abel MF: Relation of gait analysis to gross motor function in cerebral palsy. Dev Med Child Neurol, 1996, 38: 389-396. [Medline] [CrossRef]

18) Palisano R, Rosenbaum $P$, Walter $S$, et al.: evelopment and reliability of a system to classify gross motor function in children with cerebral palsy. Dev Med Child Neurol, 1997, 39: 214-223. [Medline] [CrossRef]

19) Sanders JO, McConnell SL, King R, et al.: A prospective evaluation of the WeeFIM in patients with cerebral palsy undergoing orthopaedic surgery. J Pediatr Orthop, 2006, 26: 542-546. [Medline] [CrossRef]

20) Ottenbacher KJ, Msall ME, Lyon NR, et al.: Interrater agreement and stability of the Functional Independence Measure for Children (WeeFIM): use in children with developmental disabilities. Arch Phys Med Rehabil, 1997, 78: 1309-1315. [Medline] [CrossRef]

21) Lieber RL, Friden J: Functional and clinical significance of skeletal muscle architecture. Muscle Nerve, 2000, 23: 1647-1666. [Medline] [CrossRef]

22) Thompson N, Stebbins J, Seniorou M, et al.: Muscle strength and walking ability in diplegic cerebral palsy: implications for assessment and management. Gait Posture, 2011, 33: 321-325. [Medline] [CrossRef] 